\title{
Management of Vasculitic Glomerulonephritis
}

\author{
Eveline $Y$. Wu, MD ${ }^{1, *}$ \\ William F. Pendergraft III MD, PhD $D^{2,3}$ \\ Patrick H. Nachman, MD
}

\author{
Address \\ ${ }^{*}, 1$ Division of Allergy, Immunology, and Rheumatology, Department of Pediatrics, \\ University of North Carolina at Chapel Hill, 030 MacNider Hall, CB\#7231, Chapel \\ Hill, NC, 27599, USA \\ Email: eywu@email.unc.edu \\ ${ }^{2}$ Division of Nephrology, Department of Medicine, University of North Carolina \\ Kidney Center, Chapel Hill, NC, 27599, USA \\ ${ }^{3}$ Broad Institute of Harvard and MIT, Cambridge, MA, 02142, USA
}

Published online: 18 April 2016

(C) Springer International Publishing AG 2016

This article is part of the Topical Collection on Vasculitis

Keywords Vasculitis - Glomerulonephritis · ANCA-associated vasculitis · IgA vasculitis - Cryoglobulinemic vasculitis

\section{Opinion statement}

Small-vessel vasculitides (SVV) are a group of complex and chronic systemic autoimmune disorders associated with significant morbidity. Renal involvement is a major determinant of long-term outcome in all SVV. Depending on the disorder, SVV can be associated with frequent, and often life-threatening, relapses and increased burden from long-term exposure to toxic therapies and accumulating, irreversible organ damage. Prompt diagnosis or determination of active disease and quick initiation of appropriate treatment are therefore paramount in the management of SVV. For rapidly progressive glomerulonephritis or other severe, life-threatening manifestations in either anti-neutrophil cytoplasmic antibody (ANCA)-associated vasculitis (AAV) or cryoglobulinemic vasculitis (CV), we recommend intravenous pulse methylprednisolone, plasmapheresis, and intravenous monthly cyclophosphamide. Hemodialysis is also used when indicated. Dose adjustments are made based on the patient's weight, degree of renal impairment, and tolerability. Corticosteroids and plasmapheresis are tapered according to the patient's response. Although a clearer role for rituximab in the treatment of AAV and CV is emerging, we reserve rituximab for disease relapse or disease refractory to the aforementioned treatments. We also use rituximab in less severe disease and for maintenance of remission in $\mathrm{AAV}$ and $\mathrm{CV}$ when indicated. Corticosteroids are a mainstay of therapy in IgA nephropathy (IgAN) and vasculitis (IgAV). In rapidly progressive glomerulonephritis due to IgAN or IgAV, we recommend intravenous cyclophosphamide. Again, dose adjustments are made based on the patient's weight, degree of renal impairment, and tolerability. 


\section{Introduction}

Vasculitis is a term for a group of rare disorders that share the defining feature of inflammation of blood vessel walls. They are mainly categorized by vessel size and include large-, medium-, and small-vessel vasculiti-

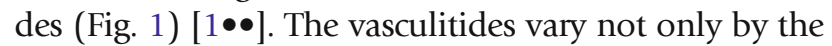
type of vessel involved but also by etiology, pathogenesis, organ involvement, and severity. The kidney is commonly affected and may even be the first expression of systemic vasculitis. Small-vessel vasculitis is the most frequent vasculitic lesion in the kidney and typically manifests as a glomerulonephritis $[1 \bullet \bullet, 2,3]$. The large- and medium-vessel vasculitides may affect the kidney but do not typically cause glomerular disease $[2,3]$. Glomerulonephritis is therefore exclusive to small-vessel vasculitis, and its presence may be helpful in evaluating vasculitis affecting the kidney.

The prognosis of vasculitic glomerulonephritis depends on early diagnosis and prompt initiation of treatment in order to prevent permanent loss of renal function [4]. Management of vasculitic glomerulonephritis is based on the underlying cause, and the optimal treatment in each is still debated. Corticosteroids are a mainstay in the treatment of systemic vasculitis, and they are often used in combination with other immunosuppressive agents $[4,5]$. In the setting of kidney failure or other severe systemic manifestations, plasma exchange is also often used as adjunct therapy. Maintenance therapy is instituted once disease remission is achieved and often includes tapering doses of oral corticosteroids and less toxic immunosuppressants. Although various guidelines review available treatment options, the optimal treatment dosing and duration of therapy are not precisely known.

The efficacy of current therapeutic regimens has certainly improved long-term survival in vasculitis with renal involvement. The use of many of these agents, however, is limited by their toxicities, and strategies to minimize therapy-related complications are therefore equally important in management. The safety and efficacy of conventional treatments used in vasculitis are being determined more rigorously in the setting of prospective, randomized clinical trials. Increasing insight into the pathophysiology of vasculitis has also led to the development of new, and potentially less toxic, therapeutic alternatives. This review focuses on recent evidence relevant to the current management of select forms of small-vessel vasculitides that exhibit a predilection for renal involvement, including the antineutrophil cytoplasmic antibody-associated vasculitides, immunoglobulin A (IgA) vasculitis (formerly called Henoch-Schönlein purpura), and cryoglobulinemic vasculitis.

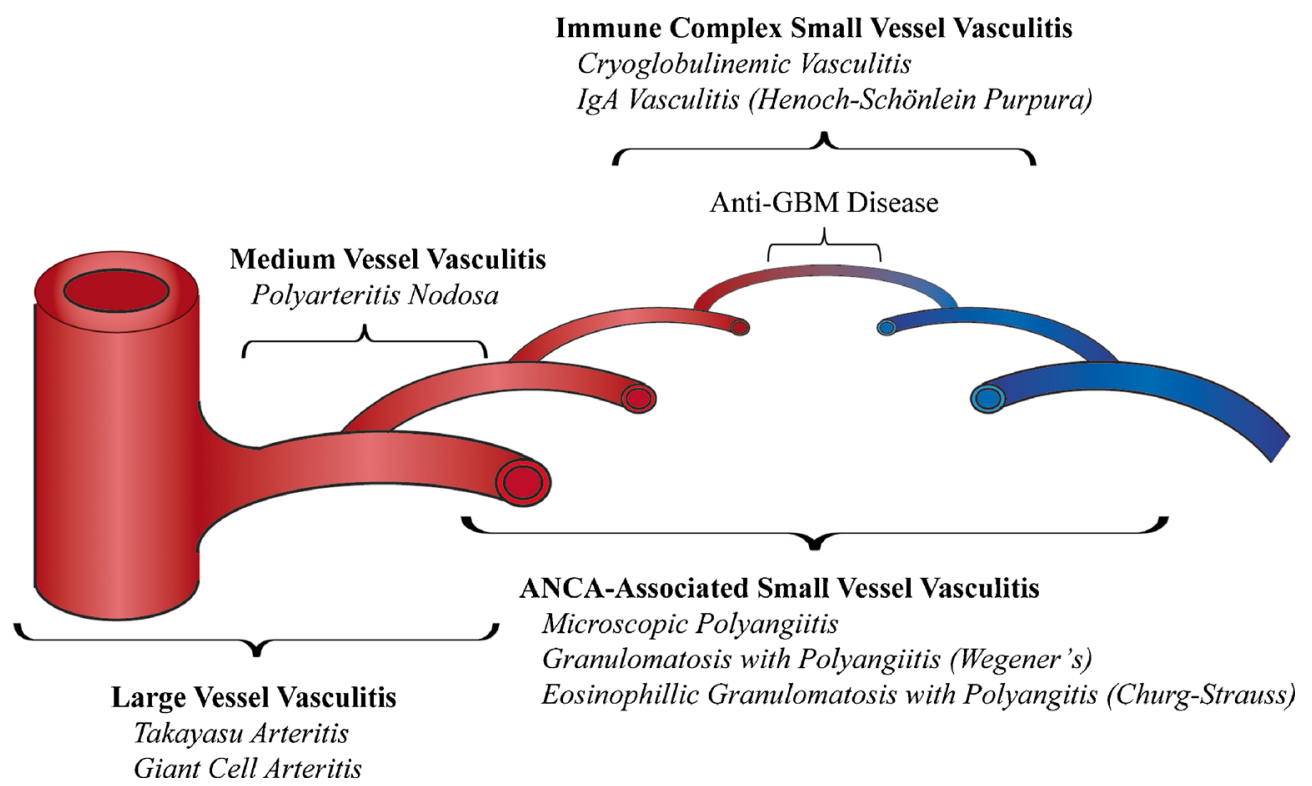

Fig. 1. Distribution of systemic vasculitis by predominant vessel involvement. Figure provided courtesy of Erin Wilfong, MD, PhD. 


\section{ANCA-associated vasculitides}

Anti-neutrophil cytoplasmic autoantibodies (ANCA), directed against the neutrophil granule proteins myeloperoxidase (MPO) and/or proteinase 3 (PR3), are directly pathogenic, and cause small- and medium-vessel vasculitides [6•]. The major forms of ANCA vasculitis are microscopic polyangiitis (MPA), granulomatosis with polyangiitis (GPA, formerly known as Wegener's granulomatosis), and eosinophilic granulomatosis with polyangiitis (EGPA, formerly known as Churg-Strauss syndrome).

The most commonly recognized presentation of ANCA-associated vasculitis (AAV) is the pulmonary-renal syndrome, with alveolar hemorrhage and kidney injury that typically manifests as a rapidly progressive glomerulonephritis. The presentation can, however, be influenced to some extent by the type of disease (i.e., GPA versus MPA), as well as the duration of disease prior to coming to the attention of an appropriate healthcare provider. In terms of kidney involvement, both GPA and MPA can present with severe kidney failure, at times requiring dialysis at presentation. EGPA less commonly involves the kidneys, and when it does, kidney disease tends to be less severe than in GPA or MPA. Dysmorphic hematuria with or without red blood cell casts, proteinuria, and an elevated serum creatinine are all clues to the diagnosis. Proteinuria is typically within the nephritic range ( $<3 \mathrm{~g} /$ day), but nephrotic-range proteinuria does not exclude AAV. Kidney disease can also occur absent other clinical manifestations [7].

Most data on the incidence and prevalence of AAV come from studies in Caucasian populations of European descent, although there are also emerging data from Asia and parts of the Middle East. The average incidence of AAV in Japan appears to be similar to that in the UK, which have 22.6 and 21.8 cases per million individuals annually, respectively [8]. Collectively, there is believed to be an overall incidence of approximately 10-20 cases per million individuals annually in Caucasian patients of European descent [9]. There are also multiple reports that demonstrate differences in incidence relative to latitude. A north-tosouth positive gradient has been observed in the Southern Hemisphere, and a south-to-north positive gradient is seen in the Northern Hemisphere. In other words, the incidence of AAV appears to correlate with proximity to the equator. This association was apparent in a study from New Zealand, located in the Southern Hemisphere, where an increase in the incidence of GPA was noted moving from north to south [10]. A second study comparing the incidence of $\mathrm{AAV}$ in two regions of Europe (Norwich, UK, latitude $52^{\circ} \mathrm{N}$; Lugo, Spain, $43^{\circ} \mathrm{N}$; both in the Northern Hemisphere) found a higher incidence of GPA in Norwich, the more northerly latitude, than in Lugo, even though the overall incidence of AAV was nearly identical [11]. Interestingly, no such difference has been noted in MPA or EGPA.

The average age of disease onset varies somewhat within populations, but occurs predominantly in the sixth and seventh decades of life. The relationship of disease to this demographic may be somewhat skewed since, when evaluated retrospectively, a number of patients arguably have evidence of disease years prior to diagnosis. Diagnostic delays are well documented in the literature [12]. Furthermore, most studies of disease do not include pediatric patients, and it is important to remain cognizant that AAV can occur at any age [13]. 


\section{Treatment}

With regard to disease pathogenesis, the overall working model involves ANCA binding to MPO and/or PR3 on the surface of neutrophils and monocytes, which, in turn, causes cellular degranulation and release of toxic granule constituents into the extracellular small-vessel vasculature. Ensuing inflammation causes histopathologic changes consistent with small-vessel vasculitis. There are also emerging data that activation of the alternative complement pathway is involved in the pathognomonic inflammation [6•].

\section{Diet and lifestyle}

- There are no dietary associations with AAV that have been recognized; however, there are known legal and illegal drugs associated with development of the disease, including hydralazine, propylthiouracil, minocycline, and levamisole-adulterated cocaine. Serologically, patients generally have anti-MPO autoantibodies at high titers; dual positivity is rare. Patients also tend to be positive for other autoantibodies, including anti-nuclear autoantibodies (ANA), anti-double-stranded DNA (anti-dsDNA) autoantibodies, anti-histone autoantibodies, anti-lactoferrin autoantibodies, and other forms of ANCA, specifically anti-human neutrophil elastase (HNE) autoantibodies. In both illicit and prescription drug-induced AAV, cessation of the causative agent is imperative. Management otherwise is the same as in the idiopathic forms of disease (e.g., immunosuppressants, and plasmapheresis and hemodialysis as indicated by disease severity). Unfortunately, little is known regarding mechanisms underlying druginduced forms of disease [14].

- With regard to lifestyle, there is a known association with silica and development of AAV, suggesting that silica may serve as an environmental trigger [15].

\section{Pharmacologic treatment}

\section{Corticosteroids}

- As is the case for many, if not all, autoimmune conditions, corticosteroids, which are relatively inexpensive, have been the mainstay of treatment for AAV for decades since the initial description of the disease. Standard treatment regimes include intravenous bolus doses of methylprednisolone followed by extended oral prednisone tapers until the disease is quiescent. Judicious use and careful monitoring for complications are recommended in patients with any form of hyperglycemia.

- It is important to note that corticosteroid use in AAV has been shown to be of little utility after the 6-month mark of therapy and that subsequent use is only shown to increase morbidity [16].

\section{Cyclophosphamide}

- Cyclophosphamide in combination with corticosteroids has been used historically as induction therapy for AAV. Fauci and colleagues were 


\section{CD20 blockade}

Alternative therapies

- Great strides have been made using rituximab-induced CD20-positive $B$ cell depletion for induction of remission in AAV.

- Rituximab, a chimeric murine/human monoclonal antibody that depletes B cells by binding CD20 and inducing antibody-dependent cellular cytotoxicity, has been reported to be non-inferior to cyclophosphamide for induction therapy in GPA and MPA in short- and

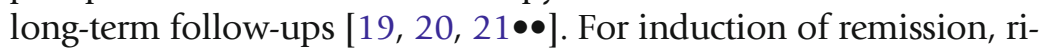
tuximab is most commonly given as four weekly infusions of $375 \mathrm{mg} /$ $\mathrm{m}^{2} /$ dose (maximum $1 \mathrm{~g}$ ) or two infusions of $750 \mathrm{mg} / \mathrm{m}^{2} /$ dose (maximum $1 \mathrm{~g}$ ) separated by 2 weeks.

- Rituximab is now approved by the Food and Drug Administration and European Medicines Agency for use as an induction therapy in patients with GPA and MPA.

- B cell depletion to durably maintain remission is a logical next step, and there are numerous case reports, case series, and retrospective studies that suggest efficacy of this strategy $[22 \bullet, 23]$. The MAINRITSAN 1 trial (NCT00748644) in France showed that rituximab ( 2 infusions of $500 \mathrm{mg}$ separated by 2 weeks every 6 months $\times 3$ courses) is superior to azathioprine ( $2 \mathrm{mg} / \mathrm{kg} / \mathrm{day}$ for 12 months, then $1.5 \mathrm{mg} / \mathrm{kg} /$ day for 6 months, and then $1 \mathrm{mg} / \mathrm{kg} /$ day for 4 months) at maintaining remission

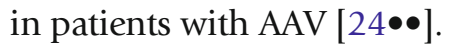

- Of note, there are several alternative drug options for maintenance of immunosuppression, including azathioprine, mycophenolate mofetil, methotrexate, and leflunomide. Controlled trials of these various options are limited. A meta-analysis looking at the comparative efficacy of azathioprine, mycophenolate mofetil, methotrexate, and leflunomide found a $55 \%$ probability that leflunomide is superior to the other three agents for remission maintenance [25]. However, true head-to-head comparisons are lacking. Therefore, provider preference, patient tolerance, cost, and risk of drug-specific adverse effects all play a role in which medication is selected. 
Apheresis

- The role of apheresis in AAV is primary given the pathogenetic import of the autoantibodies themselves.

- Treatment with plasma exchange is superior to immunosuppression without plasma exchange given the results of the MEPEX trial for patients with AAV affecting the kidneys [26].

- The PEXIVAS trial is currently underway to determine the efficacy of plasma exchange in AAV among patients with milder forms of disease (NCT00987389).

\section{Emerging therapies}

Alternative complement pathway blockade

- Novel treatment strategies aimed at other components of the inflammatory process, such as alternative complement pathway activation, are also needed. Alternative complement activation pathway products in kidney tissue $(\mathrm{Bb})$ and urine $(\mathrm{Bb}, \mathrm{C} 3 \mathrm{a}, \mathrm{C} 5 \mathrm{a}$, and soluble C5b-9) of patients with active disease correlate with severity of kidney injury [27•]. In the mouse model of MPO-ANCA glomerulonephritis, blockade of the $\mathrm{C} 5 \mathrm{a}$ receptor $(\mathrm{C} 5 \mathrm{aR})$ using an oral antagonist ameliorates

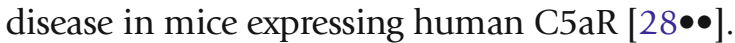

- At present, a clinical trial just completed enrollment in the USA to evaluate the safety and efficacy of human C5aR blockade to induce remission in patients with ANCA vasculitis who have mild to moderate kidney involvement (NCT01363388).

\section{Pediatric considerations}

\section{IgA vasculitis}

At diagnosis, $80 \%$ of children with AAV have significant renal impairment, and 20-30\% require dialysis [29, 30]. This loss of renal function is rarely completely reversible, and $80 \%$ children will have chronic kidney disease after long-term follow-up [29, 30]. In addition, disease-free remission is rare, and $80 \%$ of children will experience one or more disease relapses $[31,32]$. No clinical trials have been conducted in pediatric AAV, and almost all knowledge about optimal treatment and outcomes has been extrapolated from adult studies or collected from small case series. Pediatric patients are often given remission-induction treatment with corticosteroids and cyclophosphamide [33]. Rituximab is recommended in refractory or relapsing disease [33]. Methotrexate, mycophenolate mofetil, or azathioprine is often used in maintenance therapy $[33,34]$. Drug dosages need to be adjusted by the child's weight and renal impairment if present.

IgA vasculitis (IgAV), formerly called Henoch-Schönlein purpura, is characterized by the deposition of IgA-containing immune complexes 


\section{Treatment}

in the walls of small vessels [1••]. The disease is rare in adults with an estimated incidence of 0.1 to $1.8 / 100,000 /$ year [35]. The mean age at diagnosis ranges from 45 to 50 years [36]. The classic tetrad of IgA vasculitis includes non-thrombocytopenic palpable purpura, arthritis and/or arthralgia, abdominal pain, and renal disease. Compared to children, adults with IgAV have a lower frequency of abdominal pain and fever [37]. Adults, however, have a higher frequency of joint pain and a significantly higher frequency and severity of renal involvement [37-39]. Kidney disease has been reported in 30-38 \% of adults with IgAV, resulting in end-stage kidney disease in $11 \%[35,40]$. The glomerular lesions seen in IgAV are pathologically indistinguishable from those of IgA nephropathy (IgAN) and are characterized by the predominant mesangial deposition of IgA (mostly represented by subclass IgA1). IgAV is considered a systemic form of IgAN. Renal pathologic prognostic factors described for IgAN appear to be applicable for renal outcomes in IgAV [41•]. Although many patients with IgAV present with less severe renal impairment and glomerular lesion on kidney biopsy than patients with IgAN, the renal prognosis is similar in both diseases after accounting for baseline characteristics and treatment [41•]. There is very limited direct evidence-based information to guide the treatment of adult patients with IgAV. Treatment guidelines have therefore mostly been extrapolated from studies of IgAN.

\section{Diet and lifestyle}

- There is an epidemiologic association between celiac disease and IgAN [42]. Such an association is also suggested with the far less common IgAV. Secretory IgA and circulating IgA immune complexes with high activity to gliadin are detected in some patients with IgAV [43]. The prevalence of celiac disease and of seropositivity for anti-endomysium IgA or IgG, anti-deaminated gliadin peptide IgA, or anti-tissue transglutaminase IgA was significantly increased among Turkish children with IgAV compared to that of healthy controls [44]. Screening for celiac disease should be considered in IgAV, especially with symptoms suggestive of gluten sensitivity.

\section{Pharmacologic treatment}

\section{Corticosteroids}

- Treatment with corticosteroids at the onset of IgAV disease does not prevent the emergence of nephritis [45].

- Treatment with corticosteroids for 6 months is suggested for patients with IgAV and persistent proteinuria $>1 \mathrm{~g}$ /day despite maximum tolerated renin-angiotensin system (RAS) blockade with an angiotensin-

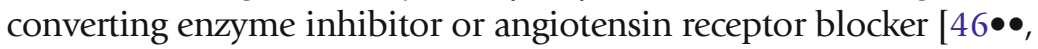
47]. In a recent large randomized control trial (RCT) in Caucasian 


\section{Cytotoxic therapies}

\section{CD20 blockade}

patients with IgAN, treatment with corticosteroids for 6 months was associated with a greater likelihood of complete remission (urine protein-to-creatinine ratio $<0.2 \mathrm{~g}$ /day with stable eGFR); corticosteroids, however, did not improve the annual decline in eGFR or the likelihood of $\mathrm{a} \geq 15-\mathrm{ml} / \mathrm{min}$ decline in eGFR from baseline [48 $\bullet$. How these results apply to patients with IgAV is unknown.

- Several corticosteroid regimens have been employed in the treatment of IgAN, without evidence of superiority of one over the other. A commonly used approach consists of intravenous methylprednisolone $1 \mathrm{~g} /$ day for 3 days at the start of months 1, 3, and 5 and oral prednisolone at a dose of $0.5 \mathrm{mg} / \mathrm{kg}$ every other day $[48 \bullet, 49,50]$.

- Patients with IgAV and a declining GFR should be treated with a course

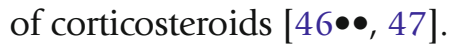

- The role of cyclophosphamide in the treatment of IgAV is poorly established. In a RCT of patients with severe IgAV, the addition of cyclophosphamide ( 6 intravenous doses of $0.6 \mathrm{~g} / \mathrm{m}^{2}$ over 4 months) to corticosteroids (intravenous methylprednisolone $7.5 \mathrm{mg} / \mathrm{kg} /$ day $\times 3$, followed by oral prednisone starting at $1 \mathrm{mg} / \mathrm{kg} / \mathrm{day}$ for 1 week, and gradually tapering over 6 months) was not associated with a demonstrable benefit at 6 months as measured by the frequency of complete remission or renal outcomes [51]. This study, however, was limited by its relatively small sample size. Treatment with cyclophosphamide in addition to corticosteroids should be considered in patients with rapidly progressive glomerulonephritis or with renal insufficiency associated with necrotizing or crescentic glomerulonephritis [48•].

- Data on the use of rituximab in IgAV is limited to small case series [52]. Rituximab treatment (total cumulative dose of $4 \mathrm{~g}$ over 1 year) was not associated with benefit over supportive therapy alone in an open-label RCT in 34 patients with IgAN and persistent proteinuria despite RAS blockade [53].

\section{Surgery}

\section{Tonsillectomy}

- The association of pharyngitis (or other infections) with acute flares of IgAN ("synpharyngitic nephritis") as well as the role of IgA1 in mucosal immunity has raised the concept of the possible benefit of tonsillectomy in the treatment of IgAN. This approach has been associated with conflicting results, but has been championed by several studies from

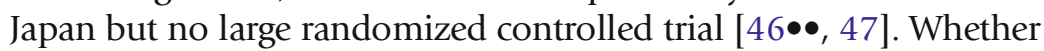
tonsillectomy is of added benefit over treatment with corticosteroids alone remains controversial, as studies have used various definitions of short-term clinical remission as the primary outcome measure (primarily based on reduction of proteinuria and stability of GFR) [54•]. 
Kidney transplantation

Although tonsillectomy has been associated with clinical remission, it is unclear to what extent, if any, it improves the long-term renal survival. Tonsillectomy has similarly been suggested in the treatment of IgAV; however, the evidence is limited to case reports and small case series [55]. Although tonsillectomy is not recommended for the routine care of patients with IgAN or IgAV, it may be considered in patients with documented recurrent relapses of IgAV or nephritis in association with recurrent bacterial tonsillitis.

- Recurrent IgA deposition is frequent in the kidney allograft after transplantation and is of unclear significance. The clinical significance of IgA deposition is frequently unclear as it may be detected in protocol biopsies without clinical signs of nephritis. Contrary to what has been previously purported, a more recent study has associated recurrent IgAN with decreased graft survival at 15 years [56]. Patient and graft survival after kidney transplantation for IgAN without recurrent disease is similar to that of controls. Similar data focused on recurrent disease after IgAV are not available.

IgAV is the most common form of systemic vasculitis in children. More than $90 \%$ of cases occur in children, with a peak incidence between 4 and 7 years of age $[36,57]$. IgAV in children has a distinct seasonal pattern with an increased incidence in the fall and winter months in contrast to that of adults. The disease is milder and spontaneously resolves in $90 \%$ of children [57]. Renal involvement is the main determinant of prognosis, and nephritis is estimated to occur in $30 \%$ of children with IgA vasculitis [58•].

The basic principles of supportive care in children with IgAV are similar to those in adults. As in adults, there is no evidence that the use of corticosteroids prevents the development of nephritis in children with IgAV $[59,60 \bullet \bullet$. Corticosteroids may have a role for children with severe disease requiring hospitalization, severe abdominal pain, or other severe gastrointestinal complications [61, 62]. The use of corticosteroids increased the odds of resolution and reduced the mean time to resolution of abdominal pain [61].

\section{Cryoglobulinemic vasculitis}

Cryoglobulinemia refers to the presence of immunoglobulins in serum that precipitate in cold temperature and dissolve on rewarming [63, 64]. Cryoglobulins are classified into three types based on type and clonality of immunoglobulins [65, 66]. Type I consists of monoclonal immunoglobulin (Ig) and is typically associated with lymphoproliferative diseases. Type II cryoglobulins are usually a mixture of monoclonal IgM and polyclonal IgG, while type III cryoglobulins are composed of polyclonal Ig. In types II and III cryoglobulins, the 
IgM fraction typically has rheumatoid factor activity. Types II and III cryoglobulins are also referred to as mixed-type cryoglobulinemia (MC) and are often secondary to an underlying disorder, including autoimmune disease, infection, or malignancy [64]. The most common cause of $\mathrm{MC}$ is chronic hepatitis $\mathrm{C}$ virus (HCV) infection [63, 64]. Essential MC refers to the absence of underlying disease and accounts for $10 \%$ of all MC $[64,67,68]$.

Not all individuals with cryoglobulins are symptomatic or develop vasculitis. The most frequent clinical manifestations are petechiae, purpura, peripheral neuropathy, and renal disease [67, 69, 70]. Other clinical manifestations include fever, weakness, myalgia, arthralgia, arthritis, and lung disease [71]. The histopathologic hallmark of mixed cryoglobulinemic vasculitis (CV) is a small-to-medium-vessel vasculitis due to deposition of cryoglobulin-containing immune complexes and complement activation $[1 \bullet \bullet, 72]$.

Renal involvement occurs in $20-30 \%$ of MC cases and typically presents with proteinuria and microscopic hematuria with mild to moderate renal insufficiency $[67,69,70]$. The most common histologic pattern on renal biopsy is membranoproliferative glomerulonephritis with depositions of Ig and complement in the subendothelium $[70,73,74]$. Other histologic patterns noted include mesangial glomerulonephritis, segmental and focal glomerulonephritides, and membranous glomerulonephritis [70, 71]. The presence of kidney disease is associated with worse prognosis and increased mortality risk in CV [69].

Treatment of $\mathrm{CV}$ is tailored according to the underlying disorder and the severity of the disease. The goals of treatment include eradication of an underlying disease if present, symptomatic relief, and containment of vasculitis to reduce irreversible organ damage. Regardless of etiology, immunosuppressive therapies should be used in cases of rapidly progressive, organ-threatening, or life-threatening disease [75].

\section{Treatment}

\section{Diet and lifestyle}

- There are small studies and case series that suggest a low-antigencontent (LAC) diet may reduce symptoms and decrease the amount of circulating immune complexes $[76,77]$. Depending on the study, the LAC consisted mainly of vegetables, fruits, and rice. A LAC diet can be considered supportive, should not be used alone in moderate to severe disease, and does not alter the natural course of the disease.

\section{Pharmacologic treatment}

Antiviral therapy

- Pegylated interferon- $\alpha$ (PEG-IFN) combined with ribavirin is considered standard of care for HCV treatment [75, 78]. Treatment with PEGIFN $(1.5 \mu \mathrm{g} / \mathrm{kg} /$ week) plus ribavirin (800-1200 mg/kg/day) results in 


\section{Corticosteroids}

Cytotoxic therapies

- There are no rigorous studies evaluating the use of corticosteroids in the treatment of CV. High-dose or pulse corticosteroid therapy is indicated for severe disease manifestations, including glomerulonephritis [86]. Short bursts of low-intermediate doses of corticosteroids may be considered for disease flares, but more chronic treatment should be avoided, due to an unfavorable side effect profile [75].

- The role of cyclophosphamide in the treatment of CV is very limited. Most of the available data is from small case reports and series and predates the discovery that HCV is a major cause of $\mathrm{CV}$ [87-90]. Cyclophosphamide has mainly been used in cases of renal involvement or severe polyneuropathy. Cyclophosphamide is typically only considered for severe disease and when other therapeutic options fail or are contraindicated. Cyclophosphamide is usually used in combination with apheresis. Typical cyclophosphamide dosing is $2 \mathrm{mg} / \mathrm{kg}$ /day orally for 2-4 months, with adjustments made for age and renal impairment. There is risk of increased viral replication with cyclophosphamide.

\section{CD20 blockade}

- Rituximab is the only biological agent that has proved effective for severe manifestations of CV. Its efficacy has been demonstrated in numerous case series and cohort studies as well as two open-label RCT $[91 \bullet, 92 \bullet]$. In the first RCT, patients were randomized to rituximab (2 doses of $1 \mathrm{~g}$ separated by 2 weeks) or conventional therapy per the treating physician (glucocorticoids alone, apheresis, cyclophosphamide, or azathioprine). The primary end point was the proportion of patients who continued taking their initial therapy at 12 months, and it was significantly higher in the rituximab group (64.3 versus $3.5 \%$ ) [91•]. In the second RCT, patients were randomized to rituximab (4 weekly infusions of $375 \mathrm{mg} / \mathrm{m}^{2} /$ dose) or to continue current immunosuppressive therapy. The primary end point was the proportion of patients who achieved clinical remission as defined by a Birmingham Vasculitis Activity Score of 0 , and it was significantly higher in the rituximab group ( 83 versus $8 \%$ ).

- Rituximab therapy is effective for glomerulonephritis due to $\mathrm{CV}$, improving or inducing remission in a majority of patients [91•, 92•, 93-96]. 
- In HCV-related CV, patients treated with rituximab combined with PEG-IFN and ribavirin have a shorter time to clinical remission, better renal response rates, and higher rates of cryoglobulin clearance compared to those treated with PEG-IFN and ribavirin alone $[97,98]$.

- Due to high risk of enhanced viral replication with HBV and HIV, rituximab should only be used if strictly needed and preferably in combination with antiviral therapy.

- Retreatment of rituximab alone at clinical relapse is effective and safe for severe manifestations of CV $[91 \bullet, 92 \bullet, 99 \bullet]$.

\section{Interventional procedures}

Apheresis

- Plasma exchange is typically reserved for severe and/or lifethreatening manifestations of $\mathrm{CV}$, including rapidly progressive glomerulonephritis requiring dialysis [90, 100, 101]. Plasma exchange may also be used with symptomatic hyperviscosity syndrome and more severe disease manifestations refractory to other therapies, such as peripheral neuropathy and cutaneous ulcers [102-104].

- Most evidence in support of plasma exchange comes from small case reports and series [90, 100-104]. Though there are earlier reports of using plasma exchange alone, it is typically used in combination with immunosuppressive therapy since plasma exchange does not prevent new cryoglobulin formation.

- Many different plasma exchange regimens have been used and vary by type of apheresis, frequency and duration of exchanges, and replacement solution used [105•]. Daily plasma exchange for $7-10$ sessions or thrice-weekly sessions for several weeks is a reasonable starting point. Sessions should then be tapered accordingly.

$\mathrm{CV}$ is very rare in children. Compared to adults, children with cryoglobulinemia have more prolonged fever, arthralgia, arthritis, and cutaneous involvement [106]. The basic principles of supportive care and treatment in children with CV are considered similar to those in adults, though there is little data. The medications used for CV in adults are also used in children, and the indications and contraindications are similar. Drug dosages need to be tailored to the child's weight. Special consideration must be given to potential side effects and to issues of compliance. Administration of live viral vaccines are avoided in children receiving immunosuppressive treatment. Longterm corticosteroids should be avoided and have undesirable adverse effects, including stunted growth. 


\section{Compliance with Ethical Standards}

\section{Conflict of Interest}

EYW declares that she has no conflicts of interest. WFP declares that he has no conflicts of interest. PHN declares that he has no conflicts of interest.

Human and Animal Rights and Informed Consent

This article does not contain any studies with human or animal subjects performed by any of the authors.

\section{References and Recommended Reading}

Papers of particular interest, published recently, have been highlighted as:

- Of importance

$\bullet \quad$ Of major importance

1.• Jennette JC, Falk RJ, Bacon PA, Basu N, Cid MC, Ferrario F, et al. 2012 revised International Chapel Hill Consensus Conference nomenclature of vasculitides. Arthritis Rheum. 2013;65(1):1-11.

This revised international nomenclature system for systemic vasculitis is the most widely used. The system has been updated and revised by including additional categories of vasculitis and adjusting names and definitions based on advances in the understanding of disease manifestations and mechanisms.

2. John R, Herzenberg AM. Vasculitis affecting the kidney. Semin Diagn Pathol. 2009;26(2):89-102.

3. Jennette JC, Falk RJ. The pathology of vasculitis involving the kidney. Am J Kidney Dis Off J Nat Kidney Found. 1994;24(1):130-41.

4. Greenhall GH, Salama AD. What is new in the management of rapidly progressive glomerulonephritis? Clinical Kidney Journal. 2015;8(2):143-50.

5. Moroni G, Ponticelli C. Rapidly progressive crescentic glomerulonephritis: early treatment is a must. Autoimmun Rev. 2014;13(7):723-9.

6. Jennette JC, Falk RJ. Pathogenesis of antineutrophil cytoplasmic autoantibody-mediated disease. Nat Rev Rheumatol. 2014;10(8):463-73.

A concise, yet thorough, review of the pathogenesis of ANCAassociated vasculitis.

7. Katsumata Y, Kawaguchi Y, Yamanaka H. Interstitial lung disease with ANCA-associated vasculitis. Clin Med Insights Circ Respir Pulm Med. 2015;9 Suppl 1:51-6.

8. Fujimoto S, Watts RA, Kobayashi S, Suzuki K, Jayne DR, Scott DG, et al. Comparison of the epidemiology of anti-neutrophil cytoplasmic antibody-associated vasculitis between Japan and the U.K. Rheumatol (Oxford, England). 2011;50(10):1916-20.
9. Ntatsaki E, Watts RA, Scott DG. Epidemiology of ANCA-associated vasculitis. Rheum Dis Clin N Am. 2010;36(3):447-61.

10. de Zoysa JR. Vasculitis in New Zealand. Clin Exp Nephrol. 2013;17(5):712-4.

11. Watts RA, Gonzalez-Gay MA, Lane SE, Garcia-Porrua C, Bentham G, Scott DG. Geoepidemiology of systemic vasculitis: comparison of the incidence in two regions of Europe. Ann Rheum Dis. 2001;60(2):170-2.

12. Poulton CJ, Nachman PH, Hu Y, McGregor JG, Jennette JC, Falk RJ, et al. Pathways to renal biopsy and diagnosis among patients with ANCA small-vessel vasculitis. Clin Exp Rheumatol. 2013;31(1 Suppl 75):S32-7.

13. Yin XL, Zou MS, Zhang Y, Wang J, Liu TL, Tang JH, et al. Twenty-three-year review of disease patterns from renal biopsies: an experience from a pediatric renal center. J Nephrol. 2013;26(4):699-707.

14. Pendergraft 3rd WF, Niles JL. Trojan horses: drug culprits associated with antineutrophil cytoplasmic autoantibody (ANCA) vasculitis. Curr Opin Rheumatol. 2014;26(1):42-9.

15. Gomez-Puerta JA, Gedmintas L, Costenbader KH. The association between silica exposure and development of ANCA-associated vasculitis: systematic review and meta-analysis. Autoimmun Rev. 2013;12(12):112935.

16. McGregor JG, Hogan SL, Hu Y, Jennette CE, Falk RJ, Nachman PH. Glucocorticoids and relapse and infection rates in anti-neutrophil cytoplasmic antibody disease. Clin J Am Soc Nephrol CJASN. 2012;7(2):240-7.

17. Fauci AS, Wolff SM, Johnson JS. Effect of cyclophosphamide upon the immune response in Wegener's granulomatosis. N Engl J Med. 1971;285(27):1493-6. 
18. Many A, Schwartz RS. On the mechanism of immunological tolerance in cyclophosphamide-treated mice. Clin Exp Immunol. 1970;6(1):87-99.

19. Jones RB, Tervaert JW, Hauser T, Luqmani R, Morgan MD, Peh CA, et al. Rituximab versus cyclophosphamide in ANCA-associated renal vasculitis. $\mathrm{N}$ Engl J Med. 2010;363(3):211-20.

20. Stone JH, Merkel PA, Spiera R, Seo P, Langford CA, Hoffman GS, et al. Rituximab versus cyclophosphamide for ANCA-associated vasculitis. N Engl J Med. 2010;363(3):221-32.

21.• Specks U, Merkel PA, Seo P, Spiera R, Langford CA, Hoffman GS, et al. Efficacy of remission-induction regimens for ANCA-associated vasculitis. N Engl J Med. 2013;369(5):417-27.

The randomized control trial demonstrates that a single course of rituximab is as effective to conventional immunosuppression with cyclophosphamide followed by azathioprine for the induction and maintenance of remission in AAV.

22. Smith RM, Jones RB, Guerry MJ, Laurino S, Catapano F, Chaudhry A, et al. Rituximab for remission maintenance in relapsing antineutrophil cytoplasmic antibody-associated vasculitis. Arthritis Rheum. 2012;64(11):3760-9.

This retrospective study suggests rituximab is effective and well tolerated for remission maintenance in AAV.

23. Pendergraft 3rd WF, Cortazar FB, Wenger J, Murphy AP, Rhee EP, Laliberte KA, et al. Long-term maintenance therapy using rituximab-induced continuous B-cell depletion in patients with ANCA vasculitis. Clin J Am Soc Nephrol CJASN. 2014;9(4):736-44.

24.• Guillevin L, Pagnoux C, Karras A, Khouatra C, Aumaitre O, Cohen P, et al. Rituximab versus azathioprine for maintenance in ANCA-associated vasculitis. N Engl J Med. 2014;371(19):1771-80.

The randomized control trial demonstrates superiority of rituximab over azathioprine for remission maintenance in AAV. 25. Hazlewood GS, Metzler C, Tomlinson GA, Gross WL, Feldman BM, Guillevin L, et al. Non-biologic remission maintenance therapy in adult patients with ANCAassociated vasculitis: a systematic review and network meta-analysis. Joint, Bone, Spine : Revue du Rhumatisme. 2014;81(4):337-41.

26. Jayne DR, Gaskin G, Rasmussen N, Abramowicz D, Ferrario F, Guillevin L, et al. Randomized trial of plasma exchange or high-dosage methylprednisolone as adjunctive therapy for severe renal vasculitis. J Am Soc Nephrol. 2007;18(7):2180-8.

27. Gou SJ, Yuan J, Wang C, Zhao MH, Chen M. Alternative complement pathway activation products in urine and kidneys of patients with ANCA-associated GN. Clin J Am Soc Nephrol CJASN. 2013;8(11):1884-91.

This study suggests urinary levels of complement activation products specific to the alternative pathway correlate with degree of kidney injury.

28.• Xiao H, Dairaghi DJ, Powers JP, Ertl LS, Baumgart T, Wang Y, et al. C5a receptor (CD88) blockade protects against MPO-ANCA GN. J Am Soc Nephrol. 2014;25(2):225-31.
This study further substantiates the role of the alternative complement pathway in the pathogenesis of AAV and identifies a novel therapeutic strategy of blocking C5a receptor.

29. Siomou E, Tramma D, Bowen C, Milford DV. ANCAassociated glomerulonephritis/systemic vasculitis in childhood: clinical features-outcome. Pediatr Nephrol (Berlin, Germany). 2012;27(10):1911-20.

30. Akikusa JD, Schneider R, Harvey EA, Hebert D, Thorner PS, Laxer RM, et al. Clinical features and outcome of pediatric Wegener's granulomatosis. Arthritis Rheum. 2007;57(5):837-44.

31. Frosch M, Foell D. Wegener granulomatosis in childhood and adolescence. Eur J Pediatr. 2004;163(8):425-34.

32. Stegmayr BG, Gothefors L, Malmer B, Muller Wiefel DE, Nilsson K, Sundelin B. Wegener granulomatosis in children and young adults. A case study of ten patients. Pediatr Nephrol (Berlin, Germany). 2000;14(3):20813.

33. Cabral DA, Uribe AG, Benseler $\mathrm{S}, \mathrm{O}^{\prime}$ Neil KM, Hashkes PJ, Higgins G, et al. Classification, presentation, and initial treatment of Wegener's granulomatosis in childhood. Arthritis Rheum. 2009;60(11):3413-24.

34. Weiss PF. Pediatric vasculitis. Pediatr Clin N Am. 2012;59(2):407-23.

35. Audemard-Verger A, Pillebout E, Guillevin L, Thervet E, Terrier B. IgA vasculitis (Henoch-Shonlein purpura) in adults: diagnostic and therapeutic aspects. Autoimmun Rev. 2015;14(7):579-85.

36. Piram M, Mahr A. Epidemiology of immunoglobulin A vasculitis (Henoch-Schonlein): current state of knowledge. Curr Opin Rheumatol. 2013;25(2):171-8.

37. Blanco R, Martinez-Taboada VM, Rodriguez-Valverde V, Garcia-Fuentes M, Gonzalez-Gay MA. HenochSchonlein purpura in adulthood and childhood: two different expressions of the same syndrome. Arthritis Rheum. 1997;40(5):859-64.

38. Calvo-Rio V, Loricera J, Mata C, Martin L, OrtizSanjuan F, Alvarez L, et al. Henoch-Schonlein purpura in northern Spain: clinical spectrum of the disease in 417 patients from a single center. Medicine. 2014;93(2):106-13.

39. Uppal SS, Hussain MA, Al-Raqum HA, Nampoory MR, Al-Saeid K, Al-Assousi A, et al. Henoch-Schonlein's purpura in adults versus children/adolescents: a comparative study. Clin Exp Rheumatol. 2006;24(2 Suppl 41):S26-30.

40. Coppo R, Andrulli S, Amore A, Gianoglio B, Conti G, Peruzzi L, et al. Predictors of outcome in HenochSchonlein nephritis in children and adults. Am J Kidney Dis Off J Nat Kidney Found. 2006;47(6):993-1003.

41. $\quad$ Oh HJ, Ahn SV, Yoo DE, Kim SJ, Shin DH, Lee MJ, et al. Clinical outcomes, when matched at presentation, do not vary between adult-onset Henoch-Schonlein purpura nephritis and IgA nephropathy. Kidney Int. 2012;82(12):1304-12.

This study demonstrates that, after accounting for baseline characteristics and treatment, the renal prognoses in IgAV and IgAN are similar. 
42. Welander A, Sundelin B, Fored M, Ludvigsson JF. Increased risk of IgA nephropathy among individuals with celiac disease. J Clin Gastroenterol.

2013;47(8):678-83.

43. Moja P, Quesnel A, Resseguier V, Lambert C, Freycon F, Berthoux $\mathrm{F}$, et al. Is there IgA from gut mucosal origin in the serum of children with Henoch-Schonlein purpura? Clin Immunol Immunopathol.

1998;86(3):290-7.

44. Soylu A, Ozturk Y, Dogan Y, Ozmen D, Yilmaz O, Kuyum $P$, et al. Screening of celiac disease in children with Henoch-Schoenlein purpura. Rheumatol Int. 2016.

45. Chartapisak W, Opastirakul S, Hodson EM, Willis NS, Craig JC. Interventions for preventing and treating kidney disease in Henoch-Schonlein Purpura (HSP). Cochrane Database of Syst Rev. 2009;(3):Cd005128.

46.• Chapter 10: Immunoglobulin A nephropathy. Kidney Int Suppl. 2(2):209-17.

The publication provides a thorough review and summary of the literature regarding the treatment of primary IgAN.

47. Chapter 11: Henoch-Schonlein purpura nephritis. Kidney Int suppl.2(2):218-20.

48. Rauen T, Eitner F, Fitzner C, Sommerer C, Zeier M, Otte $\mathrm{B}$, et al. Intensive supportive care plus immunosuppression in IgA nephropathy. N Engl J Med. 2015;373(23):2225-36.

The randomized control trial demonstrates that addition of corticosteroid therapy for persistent proteinuria despite maximum renin-angiotensin system blockade is associated with a greater likelihood of clinical remission, but does not improve the annual decline in eGFR and is associated with many adverse effects.

49. Pozzi C, Bolasco PG, Fogazzi GB, Andrulli S, Altieri P, Ponticelli C, et al. Corticosteroids in IgA nephropathy: a randomised controlled trial. Lancet (London, England). 1999;353(9156):883-7.

50. Pozzi C, Andrulli S, Del Vecchio L, Melis P, Fogazzi GB, Altieri $\mathrm{P}$, et al. Corticosteroid effectiveness in IgA nephropathy: long-term results of a randomized, controlled trial. J Am Soc Nephrol. 2004;15(1):157-63.

51. Pillebout E, Alberti C, Guillevin L, Ouslimani A, Thervet E. Addition of cyclophosphamide to steroids provides no benefit compared with steroids alone in treating adult patients with severe Henoch Schonlein purpura. Kidney Int. 2010;78(5):495-502.

52. Donnithorne KJ, Atkinson TP, Hinze CH, Nogueira JB, Saeed SA, Askenazi DJ, et al. Rituximab therapy for severe refractory chronic Henoch-Schonlein purpura. J Pediatr. 2009;155(1):136-9.

53. Lafayette RA, Canetta PA, Rovin BH, Appel GB, Hogan $\mathrm{MC}$, Erickson SB, et al. A randomized trial of rituximab in advanced IgA nephropathy. J Am Soc Nephrol. 2015;26(Abstract Edition):B5.

54. $\quad$ Liu LL, Wang LN, Jiang Y, Yao L, Dong LP, Li ZL, et al. Tonsillectomy for IgA nephropathy: a meta-analysis. Am J Kidney Dis Off J Nat Kidney Found. 2015;65(1):80-7.
A meta-analysis evaluating the role of tonsillectomy in patients with IgAN.

55. Adachi M, Matsutani S. Treatment of HenochSchonlein purpura nephritis in children with tonsillectomy. Nihon Jibiinkoka Gakkai kaiho. 2006;109(9):696-702.

56. Moroni G, Longhi S, Quaglini S, Gallelli B, Banfi G, Montagnino $G$, et al. The long-term outcome of renal transplantation of IgA nephropathy and the impact of recurrence on graft survival. Nephrol Dial Transplant Off Publ Eur Dial Transplant Assoc Eur Renal Assoc. 2013;28(5):1305-14.

57. Reamy BV, Williams PM, Lindsay TJ. HenochSchonlein purpura. Am Fam Physician. 2009;80(7):697-704.

58. Davin JC, Coppo R. Henoch-Schonlein purpura nephritis in children. Nat Rev Nephrol. 2014; 10(10):563-73.

A concise review and discussion of HSP nephritis in children and its treatment.

59. Jauhola O, Ronkainen J, Koskimies O, Ala-Houhala M, Arikoski P, Holtta T, et al. Renal manifestations of Henoch-Schonlein purpura in a 6-month prospective study of 223 children. Arch Dis Child. 2010;95(11):877-82.

$60 . \bullet$ Hahn D, Hodson EM, Willis NS, Craig JC. Interventions for preventing and treating kidney disease in Henoch-Schonlein purpura (HSP). Cochrane Database Syst Rev. 2015;8:Cd005128.

Systematic review substantiating that corticosteroids do not prevent the development of kidney disease in children with IgAV.

61. Weiss PF, Feinstein JA, Luan X, Burnham JM, Feudtner C. Effects of corticosteroid on Henoch-Schonlein purpura: a systematic review. Pediatrics. 2007;120(5):1079-87.

62. Weiss PF, Klink AJ, Localio R, Hall M, Hexem K, Burnham JM, et al. Corticosteroids may improve clinical outcomes during hospitalization for Henoch-Schonlein purpura. Pediatrics. 2010;126(4):674-81.

63. Tedeschi A, Barate C, Minola E, Morra E. Cryoglobulinemia. Blood Rev. 2007;21(4):183-200.

64. Ramos-Casals M, Stone JH, Cid MC, Bosch X. The cryoglobulinaemias. Lancet (London, England). 2012;379(9813):348-60.

65. Brouet JC, Clauvel JP, Danon F, Klein M, Seligmann M. Biologic and clinical significance of cryoglobulins. A report of 86 cases. Am J Med. 1974;57(5):775-88.

66. Damoiseaux J. The diagnosis and classification of the cryoglobulinemic syndrome. Autoimmun Rev. 2014;13(4-5):359-62.

67. Trejo O, Ramos-Casals M, Garcia-Carrasco M, Yague J, Jimenez S, de la Red G, et al. Cryoglobulinemia: study of etiologic factors and clinical and immunologic features in 443 patients from a single center. Medicine. 2001;80(4):252-62.

68. Ferri C, Mascia MT. Cryoglobulinemic vasculitis. Curr Opin Rheumatol. 2006;18(1):54-63. 
69. Ferri C, Sebastiani M, Giuggioli D, Cazzato M, Longombardo G, Antonelli A, et al. Mixed cryoglobulinemia: demographic, clinical, and serologic features and survival in 231 patients. Semin Arthritis Rheum. 2004;33(6):355-74.

70. Monti G, Galli M, Invernizzi F, Pioltelli P, Saccardo F, Monteverde A, et al. Cryoglobulinaemias: a multicentre study of the early clinical and laboratory manifestations of primary and secondary disease. GISC. Italian Group for the Study of Cryoglobulinaemias. QJM Mon J Assoc Phys. 1995;88(2):115-26.

71. Ghetie D, Mehraban N, Sibley CH. Cold hard facts of cryoglobulinemia: updates on clinical features and treatment advances. Rheum Dis Clin N Am. 2015;41(1):93-108. viii-ix.

72. Ferri C. Mixed cryoglobulinemia. Orphanet J Rare Dis. 2008;3:25.

73. Tarantino A, De Vecchi A, Montagnino G, Imbasciati E, Mihatsch MJ, Zollinger HU, et al. Renal disease in essential mixed cryoglobulinaemia. Long-term followup of 44 patients. Quart J Med. 1981;50(197):1-30.

74. Beddhu S, Bastacky S, Johnson JP. The clinical and morphologic spectrum of renal cryoglobulinemia. Medicine. 2002;81(5):398-409.

75. Pietrogrande M, De Vita S, Zignego AL, Pioltelli P, Sansonno D, Sollima S, et al. Recommendations for the management of mixed cryoglobulinemia syndrome in hepatitis $\mathrm{C}$ virus-infected patients.

Autoimmun Rev. 2011;10(8):444-54.

76. Ferri C, Pietrogrande M, Cecchetti R, Tavoni A, Cefalo A, Buzzetti G, et al. Low-antigen-content diet in the treatment of patients with mixed cryoglobulinemia. Am J Med. 1989;87(5):519-24.

77. Pietrogrande M, Cefalo A, Nicora F, Marchesini D. Dietetic treatment of essential mixed cryoglobulinemia. La Ricerca in Clinica e in Laboratorio. 1986;16(2):413-6.

78. Mukhtyar C, Guillevin L, Cid MC, Dasgupta B, de Groot K, Gross W, et al. EULAR recommendations for the management of primary small and medium vessel vasculitis. Ann Rheum Dis. 2009;68(3):310-7.

79. Mazzaro C, Zorat F, Caizzi M, Donada C, Di Gennaro G, Maso LD, et al. Treatment with peg-interferon alfa$2 \mathrm{~b}$ and ribavirin of hepatitis $\mathrm{C}$ virus-associated mixed cryoglobulinemia: a pilot study. J Hepatol. 2005;42(5):632-8.

80. Cacoub P, Saadoun D, Limal N, Sene D, Lidove O, Piette JC. PEGylated interferon alfa-2b and ribavirin treatment in patients with hepatitis $C$ virus-related systemic vasculitis. Arthritis Rheum. 2005;52(3):911-5.

81. Mazzaro C, Monti G, Saccardo F, Zignego AL, Ferri C, De Vita $S$, et al. Efficacy and safety of peginterferon alfa2b plus ribavirin for HCV-positive mixed

cryoglobulinemia: a multicentre open-label study. Clin Exp Rheumatol. 2011;29(6):933-41.

This study substantiates evidence that combination of PEGIFN and ribavirin is effective and safe for treatment of HCVrelated $\mathrm{CV}$ and can result in sustained virological response as defined by undetectable HCV viremia.
82. Sawabe T, Uenotsuchi T, Imafuku S, Kohno H, Arima J, Horiuchi T. Remission of hepatitis B virus-related vasculitis with lamivudine. Ann Intern Med.

2004;140(8):672-3.

83. Stecevic V, Pevzner MM, Gordon SC. Successful treatment of hepatitis B-associated vasculitis with lamivudine. J Clin Gastroenterol. 2003;36(5):451.

84. Kawakami T, Ooka S, Mizoguchi M, Soma Y, Yamazaki M. Remission of hepatitis B virus-related cryoglobulinemic vasculitis with entecavir. Ann Intern Med. 2008;149(12):911-2.

85. Enomoto $M$, Nakanishi T, Ishii M, Tamori A, Kawada N. Entecavir to treat hepatitis B-associated cryoglobulinemic vasculitis. Ann Intern Med. 2008;149(12):912-3.

86. De Vecchi A, Montagnino G, Pozzi C, Tarantino A, Locatelli F, Ponticelli C. Intravenous methylprednisolone pulse therapy in essential mixed cryoglobulinemia nephropathy. Clin Nephrol. 1983;19(5):221-7.

87. Frankel AH, Singer DR, Winearls CG, Evans DJ, Rees AJ, Pusey CD. Type II essential mixed cryoglobulinaemia: presentation, treatment and outcome in 13 patients. Quart J Med. 1992;82(298):101-24.

88. L'Abbate A, Maggiore Q, Caccamo A, Misefari V, Bartolomeo F, Delfino D, et al. Long term effects of cryoapheresis and cytostatic treatment in essential mixed cryoglobulinemia. Int J Art Organs. 1985;8 Suppl 2:19-22.

89. Verdickt W, Dequeker J. Plasmapheresis combined with corticosteroids and cyclophosphamide in mixed monoclonal cryoglobulinaemia. Acta Clin Belg. 1982;37(4):237-40.

90. McKenzie RG, Anavekar SN, Dawborn JK, Evans SM, Ham K, McPherson G, et al. Glomerulonephritis secondary to mixed polyclonal cryoglobulinaemia: response to immunosuppression and plasmapheresis. Aust NZ J Med. 1981;11(5):529-33.

91. De Vita S, Quartuccio L, Isola M, Mazzaro C, Scaini P, Lenzi $\mathrm{M}$, et al. A randomized controlled trial of rituximab for the treatment of severe cryoglobulinemic vasculitis. Arthritis Rheum. 2012;64(3):843-53.

A small randomized control trial demonstrating that rituximab monotherapy is effective in the treatment of severe manifestations of $\mathrm{CV}$, including glomerulonephritis.

92. Sneller MC, Hu Z, Langford CA. A randomized controlled trial of rituximab following failure of antiviral therapy for hepatitis $\mathrm{C}$ virus-associated cryoglobulinemic vasculitis. Arthritis Rheum. 2012;64(3):835-42.

This study suggests rituximab monotherapy is effective in the treatment of HCV-related CV refractory to antiviral therapy.

93. Ferri C, Cacoub P, Mazzaro C, Roccatello D, Scaini P, Sebastiani $M$, et al. Treatment with rituximab in patients with mixed cryoglobulinemia syndrome: results of multicenter cohort study and review of the literature. Autoimmun Rev. 2011;11(1):48-55.

94. Terrier B, Krastinova E, Marie I, Launay D, Lacraz A, Belenotti $\mathrm{P}$, et al. Management of noninfectious mixed 
cryoglobulinemia vasculitis: data from 242 cases included in the CryoVas survey. Blood. 2012;119(25):5996-6004.

95. Quartuccio L, Soardo G, Romano G, Zaja F, Scott CA, De Marchi G, et al. Rituximab treatment for glomerulonephritis in HCV-associated mixed cryoglobulinaemia: efficacy and safety in the absence of steroids. Rheumatology (Oxford, England). 2006;45(7):842-6.

96. Roccatello D, Baldovino S, Rossi D, Mansouri M, Naretto C, Gennaro M, et al. Long-term effects of antiCD20 monoclonal antibody treatment of cryoglobulinaemic glomerulonephritis. Nephrol Dial Transplant Off Publ Eur Dial Transplant Assoc Eur Renal Assoc. 2004;19(12):3054-61.

97. Saadoun D, Resche Rigon M, Sene D, Terrier B, Karras A, Perard L, et al. Rituximab plus Peg-interferon-alpha/ ribavirin compared with Peg-interferon-alpha/ribavirin in hepatitis C-related mixed cryoglobulinemia. Blood. 2010;116(3):326-34. quiz 504-5.

98. Dammacco F, Tucci FA, Lauletta G, Gatti P, De Re V, Conteduca $\mathrm{V}$, et al. Pegylated interferon-alpha, ribavirin, and rituximab combined therapy of hepatitis $\mathrm{C}$ virus-related mixed cryoglobulinemia: a long-term study. Blood. 2010;116(3):343-53.

99. Quartuccio L, Zuliani F, Corazza L, Scaini P, Zani R, Lenzi $M$, et al. Retreatment regimen of rituximab monotherapy given at the relapse of severe HCV-related cryoglobulinemic vasculitis: long-term follow up data of a randomized controlled multicentre study. J Autoimmun. 2015;63:88-93.

This study suggests rituximab is effective and well tolerated for remission maintenance in $\mathrm{HCV}$-related $\mathrm{CV}$.
100. Ferri C, Moriconi L, Gremignai G, Migliorini P, Paleologo G, Fosella PV, et al. Treatment of the renal involvement in mixed cryoglobulinemia with prolonged plasma exchange. Nephron. 1986;43(4):246-53.

101. Bombardieri S, Ferri C, Paleologo G, Bibolotti E, Camici M, Fosella PV, et al. Prolonged plasma exchange in the treatment of renal involvement in essential mixed cryoglobulinemia. Int J Art Organs. 1983;6 Suppl 1:47-50.

102. Ferri C, Gremignai G, Bombardieri S, Moriconi L, Pontrandolfo A, Vitali C, et al. Plasma-exchange in mixed cryoglobulinemia. Effects on renal, liver and neurologic involvement. La Ricerca in Clinica e in Laboratorio. 1986;16(2):403-11.

103. Ramunni A, Lauletta G, Brescia P, Saliani MT, Montrone M, Chironna M, et al. Double-filtration plasmapheresis in the treatment of leg ulcers in cryoglobulinemia. J Clin Apher. 2008;23(3):118-22.

104. Mazzi G, Raineri A, Zucco M, Passadore P, Pomes A, Orazi BM. Plasma-exchange in chronic peripheral neurological disorders. Int J Art Organs. 1999;22(1):40-6.

105. Rockx MA, Clark WF. Plasma exchange for treating cryoglobulinemia: a descriptive analysis. Transfus Apheresis Sci Off J World Apheresis Assoc Off J Eur Soc Haemapheresis. 2010;42(3):247-51.

A nice literature review evaluating the role of plasmapheresis and different regimens in treatment of CV.

106. Liou YT, Huang JL, Ou LS, Lin YH, Yu KH, Luo SF, et al. Comparison of cryoglobulinemia in children and adults. J Microbiol Immunol Infect. 2013;46(1):5964. 